\title{
Erratum to "Long-Term Followup of Adolescent and Young Adult Females with Hypergonadotropic Hypogonadism"
}

\author{
Pantelis Tsimaris, Nikolaos Vrachnis, Zoe Iliodromiti, and Efthymios Deligeoroglou \\ 2nd Department of Obstetrics and Gynecology, University of Athens Medical School, Aretaieio Hospital, 11526 Athens, Greece \\ Correspondence should be addressed to Nikolaos Vrachnis, nvrachnis@med.uoa.gr \\ Received 9 May 2012; Accepted 10 May 2012
}

Copyright ( $) 2012$ Pantelis Tsimaris et al. This is an open access article distributed under the Creative Commons Attribution License, which permits unrestricted use, distribution, and reproduction in any medium, provided the original work is properly cited.

In the original paper, the list of authors' names was ordered incorrectly; the correct order is Pantelis Tsimaris, Nikolaos Vrachnis, Zoe Iliodromiti, and Efthymios Deligeoroglou. 


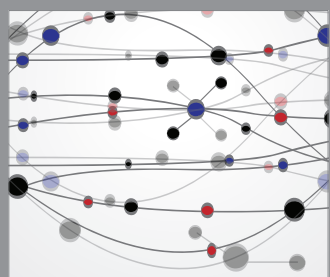

The Scientific World Journal
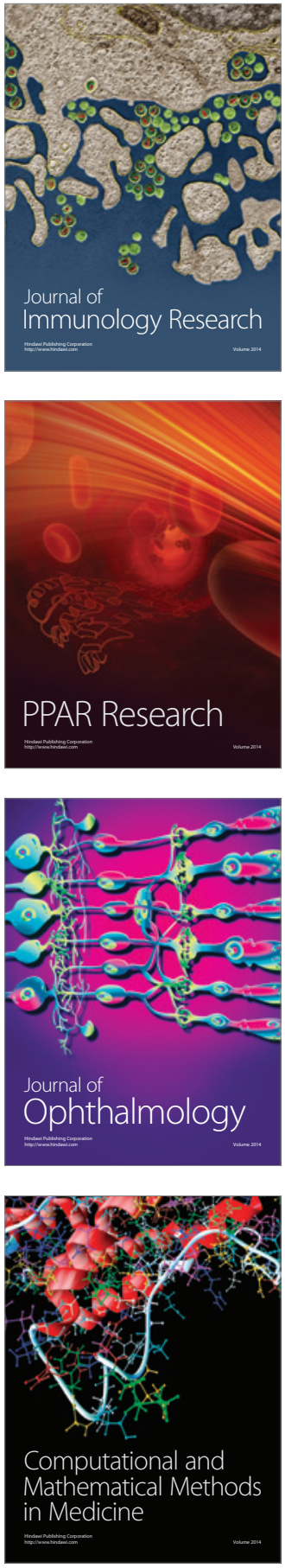

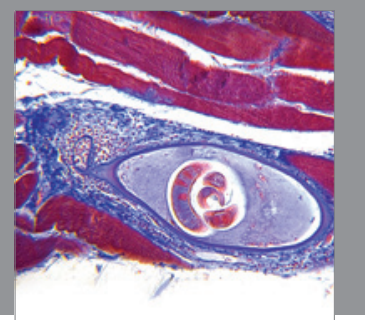

Gastroenterology

Research and Practice
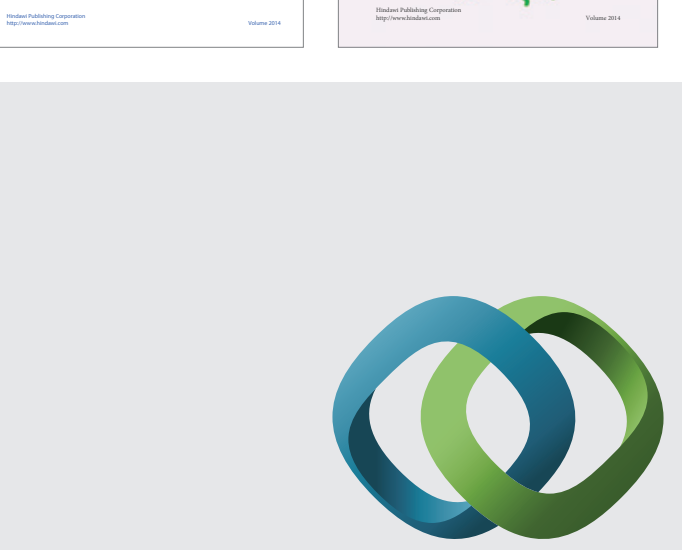

\section{Hindawi}

Submit your manuscripts at

http://www.hindawi.com
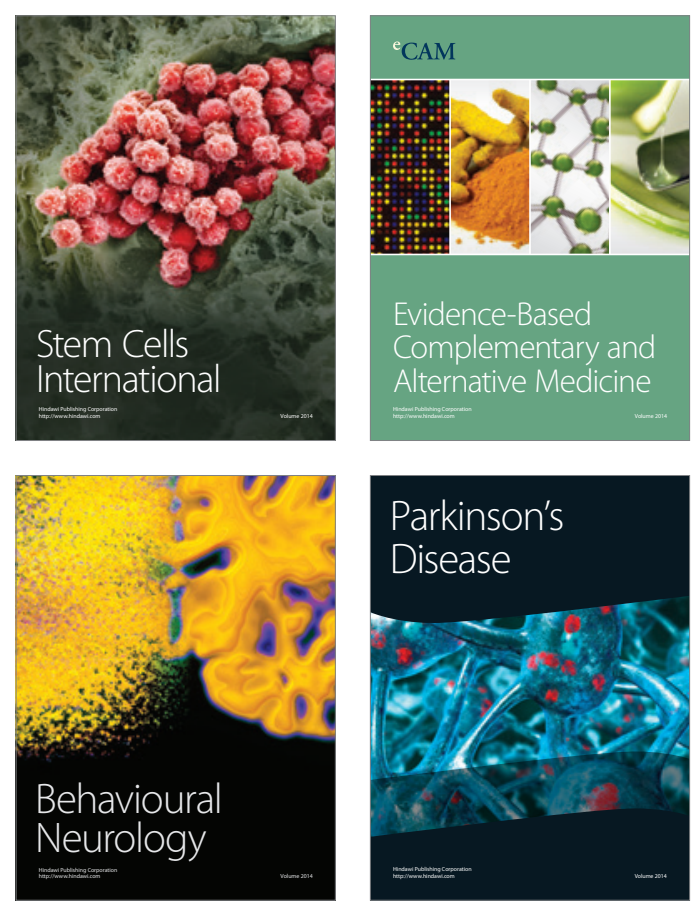

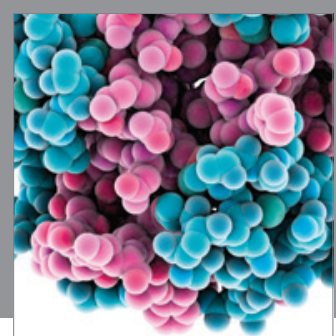

Journal of
Diabetes Research

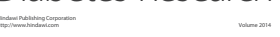

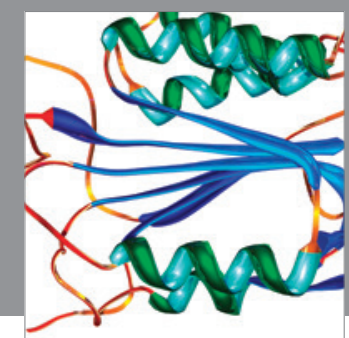

Disease Markers
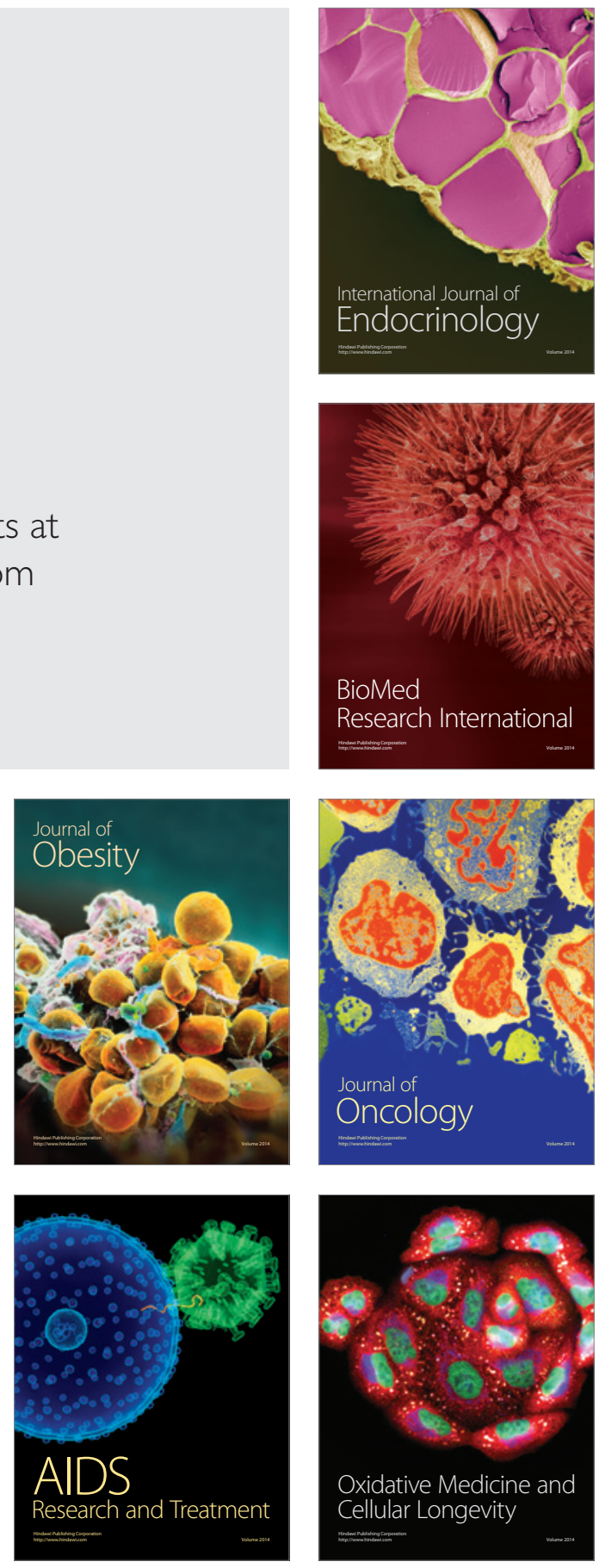